\title{
An evaluation of wild populations of perennial ryegrass from dairy farms in the Waikato and Bay of Plenty districts
}

\author{
D. RYAN ${ }^{1}$ and B.M. COOPER ${ }^{2}$ \\ ${ }^{1}$ AgResearch Ruakura Research Centre, Private Bag 3123, Hamilton \\ ${ }^{2}$ AgResearch Keri Keri, Private Bag 23, Keri Keri \\ doug.ryan@agresearch.co.nz
}

\begin{abstract}
A ryegrass breeding programme to improve the seasonal growth and plant persistence of perennial and hybrid ryegrasses in the Waikato began at AgResearch Ruakura, Hamilton in 2001. One approach was to characterise the genetic diversity of the naturalised populations within 26 dairy farms from different districts around the Waikato and Bay of Plenty (BOP) regions. Plants from 26 individual breeding lines were evaluated as single spaced plants over a 3 -year period in comparison with three commercialised ryegrass cultivars. Principal Component Analysis was used to order the plant populations in accordance with the observed plant variables of seasonal growth pattern, tillering ability, leaf size and extension, and the incidence of crown rust. A hierarchical cluster analysis of the wild populations revealed two distinct plant groups. A mix of large leaf Italian Lolium multiflorum and hybrid plants were typical from the warmer drier areas of the BOP. The Italian ryegrass was prone to severe crown rust infection whereas the hybrids were more resistant. Shorter, narrow leaved and densely tillered plants with a high rust infection dominated the Waikato populations. Ecotypes that maintained high plant tiller density throughout the seasons had the best persistence. Plants that displayed an improvement in seasonal yield and tillering over the commercial cultivars were considered an important genetic source to develop new persistent cultivars for the Waikato and BOP regions.
\end{abstract}

Keywords crown rust, drought, ecotypes, Lolium spp., plant breeding

\section{Introduction}

Performance and persistence of ryegrass (Lolium perenne) in the Waikato and Bay of Plenty (BOP) is a continuing concern (Thom et al. 1998). In 2001, AgResearch initiated a ryegrass breeding programme at Ruakura to improve the seasonal growth and characterise plants better adapted to the climatic and biotic stresses imposed by the environment. One approach was to investigate the genetic diversity within the naturalised ryegrass populations existing within individual dairy farms around different districts in the Waikato and BOP. This work evaluated plant populations taken from 26 dairy farms and compared this ecotype material with three commercial cultivars commonly in use at the time of the evaluation.

\section{Methods}

During the winter of 1994, ryegrass plants were collected from 26 dairy farms around the Waikato and BOP regions. In the BOP, nine coastal sites from Te Puna in the north to Whakatane in the south and five farms inland around Edgecombe and the Pongakawa Valley were selected. In the Waikato, twelve farms were chosen; four from Te Aroha/Wahora district, NE from Hamilton; four from Taupiri/Gordonton district, north of Hamilton and four from Ohaupo/Te Awamutu district, south of Hamilton.

At each farm, a paddock that had not been renovated for at least 20 years was selected for sampling. Sixty, 40-cm-diameter pasture cores were taken at 5-m intervals across the paddock. Cores were then sent to AgResearch Grasslands at Palmerston North where each was dissected and a single ryegrass plant consisting of two to three tillers removed and planted into a soil

Figure 1 Position of the 26 wild populations of ryegrass collected from dairy farms in the Waikato and Bay of Plenty, and of the three cultivars, as defined by the Principal Components 1 and 2.

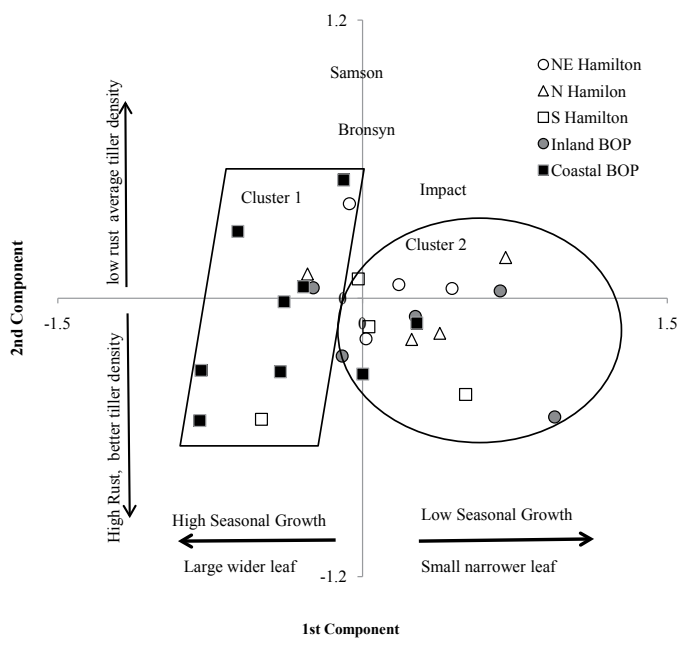


Table 1 Comparison of ryegrass plant populations from dairy farms in districts of the Waikato and Bay of Plenty (population means).

\begin{tabular}{|c|c|c|c|c|c|c|c|c|}
\hline \multirow[b]{2}{*}{ District } & \multicolumn{4}{|c|}{ Seasonal growth scores } & \multirow{2}{*}{$\begin{array}{l}\text { Leaf } \\
\text { size }\end{array}$} & \multirow{2}{*}{$\begin{array}{c}\text { Tiller } \\
\text { density }\end{array}$} & \multirow[t]{2}{*}{ Rust } & \multirow{2}{*}{$\begin{array}{c}\text { Heading } \\
\text { time }\end{array}$} \\
\hline & Autumn & Winter & Spring & Summer & & & & \\
\hline NE Hamilton & 2.40 & 2.86 & 2.97 & 2.59 & 2.10 & 3.1 & 2.1 & 1.7 \\
\hline N Hamilton & 2.30 & 2.91 & 2.91 & 2.33 & 2.13 & 3.0 & 2.0 & 1.6 \\
\hline S Hamilton & 2.32 & 3.00 & 2.98 & 2.39 & 2.10 & 2.9 & 2.0 & 1.6 \\
\hline Inland BOP & 2.10 & 2.92 & 2.91 & 2.10 & 2.13 & 3.0 & 2.0 & 1.4 \\
\hline Coastal N BOP & 2.47 & 3.32 & 3.35 & 2.52 & 2.86 & 3.1 & 2.1 & 1.9 \\
\hline Coastal S BOP & 2.53 & 3.10 & 3.20 & 2.54 & 2.32 & 3.2 & 2.1 & 1.8 \\
\hline Isd (0.05) & n.s. & 0.22 & 0.28 & 0.33 & 0.17 & n.s. & n.s. & 0.29 \\
\hline Seasonal growth scores: & \multicolumn{2}{|l|}{ Scale 1 to 5} & \multicolumn{2}{|l|}{$1=$ poor } & \multicolumn{2}{|c|}{$5=$ excellent } & & \\
\hline Leaf size: & \multicolumn{2}{|l|}{ Scale 1 to 4} & \multicolumn{2}{|l|}{1 = fine } & \multicolumn{2}{|l|}{$4=$ large } & & \\
\hline Tiller density & \multicolumn{2}{|l|}{ Scale 1 to 4} & \multicolumn{2}{|l|}{$1=$ few } & \multicolumn{2}{|l|}{4 = many } & & \\
\hline Rust & \multicolumn{2}{|l|}{ Scale 1 to 4} & \multicolumn{2}{|c|}{1 = clean green } & \multicolumn{2}{|c|}{$4=$ high infection } & & \\
\hline Heading time & \multicolumn{2}{|l|}{ Scale 1 to 3} & \multicolumn{4}{|c|}{$\begin{array}{l}1=\text { zero seed head emergence at } 1 \text { November } \\
3=\text { many seeds showing }\end{array}$} & & \\
\hline
\end{tabular}

container to encourage further plant development in a glasshouse. Plants were then transplanted into the field while being kept separated in their original farm collection groups for seed harvesting. Seed from each plant in each group was hand harvested autumn 1995 in isolation from each other, and stored in the Margot Forde Germplasm Centre as 26 individual breeding lines. Before transplant to the field, leaf sheath epidermis was stained and examined microscopically for the presence of endophyte.

In the autumn of 2001, 64 seedlings from each of the 26 lines and three commercial perennial ryegrass cultivars used as standards, (Fig. 1) all with wild type endophyte, were raised in a glasshouse at Ruakura, Hamilton. When they had developed eight to 12 tillers, they were transplanted into the field. Rows of eight plants per breeding line were planted at $30-\mathrm{cm}$ spacing in a randomised block design with eight replicated rows. The paddock had been previously cultivated following a summer fallowing to minimise potential contamination from other resident ryegrass. Annual fertiliser dressing of $350 \mathrm{~kg} 30 \%$ potash superphosphate was applied and soil $\mathrm{pH}$ maintained at 5.8 by applying lime every 2 years. After each grazing, $25 \mathrm{~kg} \mathrm{~N} / \mathrm{ha}$ was applied as urea.

Seasonal herbage growth, plant tiller density, leaf size, crown rust infection and time of heading were noted for each plant using a visual score scaling. After each plant character assessment at 3 to 4-weekly intervals during the spring and summer, twice during autumn and at the end of winter, the plants were defoliated with a mob of sheep over a 24-hour grazing period. Plant characters were assessed for 2 years. At the end of the assessment period, and again 1 year later, plant survival was recorded. A multivariate Principal Component Analysis was applied to the ecotype population means for all of the observed characters. When plotted, the components portrayed the relative performance of all the different ryegrass populations. A Hierarchical Cluster analysis was also applied to find plant populations with similar features.

\section{Results}

There were significant plant population differences between the collection sites for many of the traits noted (Table 1). The two coastal BOP sites consistently showed the best growth from the autumn to spring seasons. Large-leaved populations came from the coastal north sites whereas medium-sized leaf types came from the coastal south sites. The populations from inland BOP and Waikato were significantly smaller leaved. All sites contained plant populations with similar plant tiller density and rust infection. The coastal BOP sites were significantly earlier heading than the inland BOP populations which were later heading than the Waikato sites.

The seasonal herbage growth and the morphological features of the ecotype populations and cultivars are presented in Fig. 1. Of the total variation, $46 \%$ was explained by the first two principal components. The first component ( $\mathrm{x}$ axis) shows which ecotypes have consistently high growth in all seasons, high leaf extension and a large-leaved character towards the left hand side of the graph. Plant populations on the right hand side of the graph had poorer growth and shorter, narrower leaves. The second component (y axis) represents populations with better warm season growth, rust tolerance and average tiller density in the upper zone of the graph whilst populations in the lower zone were more susceptible to crown rust infection but 
Table 2 Percent survival of ryegrass, within each district, collected from dairy farms in the Waikato and Bay of Plenty (\% of original plantings).

\begin{tabular}{lccc}
\hline District & $\begin{array}{c}\text { Winter 2003 } \\
\text { Group mean }\end{array}$ & $\begin{array}{c}\text { Winter 2004 } \\
\text { Group mean }\end{array}$ & Range \\
\hline NE Hamilton & 65 & 59 & 47 to 66 \\
N Hamilton & 57 & 52 & 38 to 66 \\
S Hamilton & 53 & 50 & 39 to 61 \\
BOP Inland & 55 & 46 & 27 to 64 \\
BOP Coastal & 62 & 55 & 44 to 75 \\
Cultivars & 70 & 63 & - \\
\hline
\end{tabular}

had higher plant tiller density.

The cluster analysis indicated that the ecotype populations formed two distinct groups. Those ecotypes in Cluster 1, (Figure 1), were mainly from the coastal areas of the BOP with three populations from the Waikato. Cluster 2 ecotypes were from inland BOP and the Waikato. The most distinguishing feature between the two groups was plants from coastal BOP and three populations from the Waikato were a mix of large- and medium-leaf sized hybrid and Italian ryegrass. The four populations in the bottom half of Cluster 1 were Italian ryegrass highly susceptible to crown rust. The other six ecotypes in the upper half of the cluster were medium-leaf sized hybrids with low rust infection. In contrast, the inland BOP and Waikato plants, Cluster 2 , were narrower, shorter leaved, perennial ryegrasses susceptible to the crown rust.

The ecotypes had differing heading dates with the coastal BOP populations 1 to 2 weeks earlier than the inland BOP and Waikato ecotypes (Table 1). In contrast to the standard cultivars, most ecotypes had a prolific aftermath heading or secondary flowering into the summer. Wild type endophyte infected $95 \%$ of ecotype plants; less than $1 \%$ of the large-leaf types were infected with Neotyphodium occultans.

Large plant losses occurred during the assessment phase of the evaluation, (Table 2). At the start of the third winter, ecotypes from the NE Hamilton district and the coastal BOP had lost on average up to $35 \%$ of their plant population whereas from the rest of the Waikato and inland BOP, $45 \%$ of the plant population had died. The commercial cultivars lost $30 \%$ of their plant population. Plant survival at the end of the fourth winter showed losses were minimal during the third year, with between 3 and $7 \%$ reduction in all ecotypes and cultivars compared to the previous 2 years. The inland BOP ecotypes have the widest range in plant survival compared to the coastal BOP ecotypes.

\section{Discussion}

The Waikato and BOP ryegrass populations showed a strong differentiation in plant morphology and also in proportion of species composition. This result contrasts with plant collections made in the North Island (Wedderburn et al. 1989) and in the South Island (Widdup and Ryan 1992) where sampling from a range of different environments did not reveal distinct ryegrass ecotypes. The larger-leaved Italian and hybrid ecotypes from the coastal BOP contrasted sharply with the narrow and shorter-leaved perennial ryegrass predominant among the Waikato ecotypes. This is not surprising as in the 1970 and 1980 decades, two cultivars had been produced from these short term ryegrass ecotype populations in the BOP and Waikato; Corvette from Te Puna (near Tauranga) represented by four populations in the bottom half of Cluster 1, and Concord from Orini, the NE Hamilton area (Percival et al. 1989). These populations were predominantly Italian ryegrass with some perennial traits (Forde et al. 1988) but had a common characteristic of strong spring growth. The Waikato populations, being strongly perennial types, had partly evolved from the Hawkes Bay ecotype strain which formed the cultivar Grasslands Ruanui perennial ryegrass.

The large plant loss experienced by the start of the third winter reflected the ecotypes' ability to survive the high temperatures and moisture deficits that occurred in each summer in the evaluation. There were extra stresses from rust infection reducing photosynthesis and plant roots lost or weakened by exposure to high surface soil temperature, resulting in plant pulling. No insect predation was apparent. The low plant loss after the third summer showed plants with better adaptive mechanisms for persistence; they tolerated the drought conditions, maintained good tiller density and perhaps were deeper rooting to resist the plant pulling. The coastal BOP and NE Hamilton ecotypes had the lowest plant loss relative to the other ecotypes. This suggests that in the original field plant population, the Italian ryegrass parentage evident in the more open broader leafed morphology was combined with perennial ryegrass parentage to form new perennial hybrids infected with the perennial wild type endophyte, and persistence strongly related to vegetative tillering that was not dissimilar to the Waikato ecotypes and the standard cultivars.

Greater yield potential came from the BOP ecotypes in all seasons. High levels of crown rust infection and aftermath heading are factors detrimental to ryegrass feed quality over the summer/autumn period. Plant selection of only the best genotypes from the BOP ecotypes combined with the best Waikato ecotypes without these undesirable attributes allows an opportunity to create new hybridisation breeding programmes in the Waikato. Crossing superior plant genotypes between the BOP and Waikato ecotypes will 
produce new genetic germplasm that is better adapted to the climate and grazing management systems of both regions. Although these plants were evaluated under a sheep grazing regime, the grazing rotation length and intensity of defoliation used would produce similar outcomes to those used under dairy grazing. The ecotype collection therefore, is a valuable source of genetic material to develop new persistent and productive cultivars, infected with the appropriate endophyte, for these regions.

\section{REFERENCES}

Forde, M.B.; Burgess, R.E.; Halligan, E.A.; Gardener, S.E.; Latch, G.C.M. 1988. Varieties of Italian Ryegrass in New Zealand. Proceedings NZ Grassland Association 49: 101-106.

Percival, N.S.; Gould, G.J.; Piggott, G.J.; Cranshaw, L.J. 1989. Production and persistence of short term ryegrasses in the Northern North Island. Proceedings New Zealand Grassland Association 50: 237-243.
Thom, E.R.; Waugh, C.D.; McCabe, R.J. 1998. Growth and persistence of perennial and hybrid ryegrass when grazed by dairy cows in the central Waikato region of New Zealand. New Zealand Journal of Agriculture Research 41: 477-486.

Wedderburn, M.E.; Pengelly, W.J.; Tucker, M.A.; di Menna, M.E. 1989. Description of ryegrass removed from New Zealand North Island hill country. New Zealand Journal of Agriculture Research 32: 521529.

Widdup, K.H.; Ryan D.L.; 1992. Forage potential of wild populations of perennial ryegrass collected from Southern New Zealand farms. Proceedings New Zealand Grassland Association 54: 161-165. 